\title{
doispontos:
}

\section{Sobre o uso do conceito de sublimação e suas derivações, a partir da perspectiva estética}

\section{marcuseana}

\author{
Sérgio Augusto Franco Fernandes \\ Universidade Federal do Recôncavo da Bahia (UFRB - Cachoeira/BA)
}

\begin{abstract}
Resumo: Levando em conta a obra Eros e civilização, uma interpretação filosófica do pensamento de Freud (1955), onde Herbert Marcuse enfatiza o possível papel libertador da arte, constata-se, pois, uma tentativa de aproximação das teses de Marx - sobre a exploração pelo trabalho - com as de Freud - encontradas em O mal-estar na civilização. Seu intuito, com base em tal aproximação, é apresentar as bases de uma modificação cultural e estética da civilização industrial, definindo a função da arte na sociedade moderna. Para Marcuse, isto, por si só, justifica o sentido da sua empreitada: desenvolver o projeto de uma cultura não repressiva, que permita aos homens reatarem com uma ideia "correta" de felicidade. Para tanto, se faz necessário a compreensão do conceito de sublimação, assim como suas derivações, a saber, o conceito de autossublimação e dessublimação repressiva, objetos da investigação ora proposta.
\end{abstract}

Palavras-chave: arte; autossublimação; dessublimação repressiva; Freud; Marcuse; sublimação.

Abstract: Considering the work Eros and Civilization: A Philosophical Inquiry Into Freud (1955), Herbert Marcuse emphasizes the possible liberating role of art - one finds a tentative to merge Marx's thesis - about work exploitation - with Freud's - found in the Civilization and its Discontents. His goal based in such merge is to present the basis to a cultural and esthetic modification of the industrial civilization, defining the function of the art in the modern society. To Marcuse, this point by itself justifies the meaning of his assignment, which is: to develop the project of a culture not repressed, that allows mankind to connect with the correct idea of happiness. For that, the understanding of the concept of sublimation becomes necessary as well as its derivations. The concept of self-sublimation and repressive dessublimation are the object of the proposed investigation.

Keywords: Art; Freud; Marcuse; repressive dessublimation; self-sublimation; sublimation.

Apesar da ausência, na obra freudiana, de uma teoria coesa acerca da sublimação, a utilização desse conceito se mostra recorrente em toda literatura psicanalítica, apresentando-se como referência para todo o corpo doutrinal. Constatamos, pois, que a referida ausência permanece sendo uma das lacunas do pensamento psicanalítico, o que não apequena, de forma alguma, a relevância do conceito em questão. Sigmund Freud recorreu à noção de sublimação para tentar elucidar, no transcurso da sua obra, a partir de um ponto de vista econômico e dinâmico, algumas atividades nutridas por um desejo que não almeja, de maneira manifesta, um objetivo sexual. Logo, a criação artística, a investigação intelectual e outras atividades valorizadas socialmente se apresentam como exemplos. Freud, em Moral sexual civilizada e doença nervosa moderna (1908), nos diz que a sublimação disponibiliza uma fenomenal quantidade de energia para a atividade civilizada, em função de uma particular e marcante especificidade, a saber, sua habilidade em deslocar suas metas sem restringir, de maneira considerável, a sua intensidade. Fazendo 
valer as palavras de Freud: "A essa capacidade de trocar seu objetivo sexual original por outro, não mais sexual, mas psiquicamente relacionado com o primeiro, chama-se capacidade de sublimação" (FREUD, 1988a [1908], p. 193).

Diversos autores relegam a sublimação a uma categoria teórica secundária, devido, certamente, a uma utilização abusiva do termo e da sua elucidação jamais concluída por Freud. Contudo, a nossa crença é de que a sublimação se constitui como uma noção crucial para a psicanálise, visto que se encontra justamente no entrecruzamento de diversas elaborações conceituais, seja na teoria metapsicológica das pulsões, seja na teoria dinâmica dos mecanismos de defesa do eu, seja na teoria lacaniana da Coisa (das Ding), além de ser um instrumento clínico fundamental na prática psicanalítica. Essa noção mostra-se necessária para dar coerência à teoria freudiana, apresentando-se como único conceito da psicanálise capaz de elucidar a origem sexual do impulso criador do homem.

O psicanalista Juan David Nasio nos diz o seguinte: "As raízes e a energia do processo de sublimação, portanto, são pulsionalmente sexuais (pré-genitais: orais, anais, fálicas), enquanto a conclusão desse processo é uma realização não sexual conforme aos ideais mais consumados de uma dada época" (NASIO, 1995, p. 78). Ele está se referindo à sublimação como uma maneira de modificar e potencializar a energia das pulsões sexuais, desde que seja possível convertê-las em força positiva e criadora.

Entretanto, devemos também conceber tais forças como "condimento" e, ao mesmo tempo, como arrefecimento da intensidade excessiva dessas mesmas forças. Seria nesse sentido, por exemplo, que Freud, desde os primórdios dos seus escritos, levou em conta a sublimação como sendo uma das defesas do eu contra o surgimento repentino e violento das pulsões sexuais ou, como escrevera cerca de vinte anos mais tarde, como uma das categorias de defesa contraposta à descarga direta e absoluta da pulsão. Certamente é por isso que podemos encarar o conceito de sublimação sob duas perspectivas complementares, que acabam por congregar os diferentes enfoques freudianos, quais sejam: a sublimação como expressão positiva e bem elaborada da pulsão, e a sublimação como meio de defesa capaz de conter os excessos da vida pulsional.

Vale a ressalva de que Freud sempre destacou, dentre as atividades socialmente valorizadas, a produção artística, visto que, no que tange às atividades humanas, intelectuais ou materiais, esta é, sabemos nós, a que permanece sempre um enigma. Daí, então, surgiu o interesse do pai da psicanálise pelo domínio da arte, mesmo reconhecendo sua ignorância nesta matéria. No seu estudo sobre o Moisés de Michelangelo (1914) diz ele, logo no início, que não é um conhecedor de arte, que é apenas um leigo. Considera-se incapaz de apreciar, de maneira adequada, a maioria dos métodos utilizados pelos artistas e dos efeitos obtidos em arte. Entretanto, admite que as obras de arte exercem nele um enorme fascínio, mais especificamente a literatura e a escultura, e não tanto a pintura. Notemos, portanto, que a estética, de maneira geral, inspira-lhe muita desconfiança: "Sentimo-nos cheios de admiração reverente por elas (obras de arte) e as admiramos, mas somos incapazes de dizer o que representam para nós" (FREUD, 1988b [1914], p. 253).

O enigma ao qual Freud alude e propõe decifrar mostra-se duplo: por um lado, ele concerne a razão da criação ao artista e, por outro, concerne, entre a obra de arte e o espectador, uma emoção reservada, positiva ou negativa, atrativa ou repulsiva, sendo que tal relação não deve ser tida como puramente intelectual. Argumenta Freud:

Mas, geralmente, diante de uma grande obra de arte, cada um diz algo diferente do outro e nenhum diz nada que resolva o problema para o admirador despretensioso. A meu ver, o que nos prende tão poderosamente só pode ser a intenção do artista, até onde ele conseguiu expressá-la em sua obra e fazer-nos compreendê-la. Entendo que isso não pode ser simplesmente uma questão de compreensão intelectual; o que ele visa é despertar em nós a mesma 
atitude emocional, a mesma constelação mental que nele produziu o ímpeto de criar (FREUD, 1988b [1914], p. 254).

A emoção estética provocada pela obra de arte, que muitas vezes prende fortemente o espectador, deve possuir, na sua raiz, o reconhecimento de uma semelhança, uma certa familiaridade entre as emoções e as intenções manifestadas pelo artista e pelo espectador. Sendo assim, Freud supõe que a própria obra de arte se prontifique à análise para além do efeito que pode produzir, seja atração ou fascínio, com ou sem ambiguidade. Então, para saber se fomos ou não afetados pela obra, é preciso interpretá-la, haja vista que, somente depois de interpretada, poderá ser possível conhecer os motivos pelos quais nos deixamos intensamente afetar. De acordo com Freud, podemos também tentar adivinhar a intenção do artista, desde que busquemos o sentido e o conteúdo da obra através da sua interpretação.

Vale lembrar que a descoberta do complexo de Édipo é considerada por Freud como sendo o primeiro indício de uma profunda relação entre as obras de arte e o inconsciente, visto que permite um esclarecimento, por exemplo, do comportamento aparentemente absurdo dos personagens encontrados nas ficções. Dois anos após a "descoberta" do Édipo, Freud publicou a Interpretação dos sonhos (1900), obra esta que marcou os primeiros grandes princípios da psicanálise. Todavia, a comparação entre o sonho e a obra de arte se justifica, na medida em que Freud estabelece a afinidade entre a criação artística e o sonho, entre o artista e o neurótico. Logo, o complexo de Édipo e a simbólica dos sonhos passaram a constituir, já no início do século $\mathrm{XX}$, dois instrumentos teóricos que lhe possibilitaram continuar suas reflexões sobre a arte e sobre os mecanismos da criação. A princípio, ninguém contesta a semelhança entre o sonho e a obra de arte, principalmente se forem levados em consideração os limites indicados pelo psicanalista vienense nessa comparação. Para Freud, a obra de arte estabelece uma comunicação com o público, enquanto o sonho apenas satisfaz o narcisismo do sujeito. Complementa Marc Jimenez:

O parentesco entre o neurótico e o artista é mais embaraçoso. Evidentemente, Freud tem o cuidado de precisar a diferença entre os dois: o primeiro é um associal, o segundo retoma pé na realidade graças à sublimação e à produção de obras expostas ao reconhecimento do outro (JIMENEZ, 2008, p. 267).

O mérito de Freud, de acordo com Jimenez, se encontra no apontar o prazer e o gozo que se extraem da compreensão da obra de arte. A arte seria, então, uma ilusão, um consolo para os males propiciados pela realidade, “(...) que toca a verdade de nosso ser no que há nele de mais escondido" (JIMENEZ, 2008, p. 268). Para Jimenez, Freud, psicanalista, nem marxista nem nietzscheano, aproxima-se destes ao menos no seu diagnóstico da cultura do ocidente: "A famosa felicidade, sempre prometida para o futuro, contenta-se com um pesado tributo: o do sacrifício da libido, da satisfação autêntica das pulsões, da adaptação desesperada à realidade" (JIMENEZ, 2008, p. 271).

É, pois, a partir desse diagnóstico em comum que trazemos Herbert Marcuse para a nossa discussão. Tomando a obra Eros e civilização. Uma interpretação filosófica do pensamento de Freud (1955) como sendo uma das suas mais importantes produções, buscaremos compreender, mesmo que de maneira sucinta, remetendo-nos a algumas passagens do seu texto, a utilização do conceito de sublimação e aquilo que estamos a chamar de suas derivações, a saber, o conceito de autossublimação e dessublimação repressiva, procurando, assim, melhor compreender a sua abordagem teórica acerca da possibilidade de existência de uma sociedade não reprimida, onde é enfatizado o possível papel libertador da arte.

Na referida obra, constatamos uma tentativa de aproximação das teses de Marx, acerca da exploração pelo trabalho, com as de Freud, contidas em O mal-estar na civilização (1929). Como bem diz Jimenez, "A tentativa de conciliar o autor do Capital e o fundador da psicanálise não é aberrante" (JIMENEZ, 2008, p. 340). É verdade que os dois autores sempre se mostraram preocupados com o destino do homem, vítima 
dos mais variados tipos de coerção, contudo, o intuito de Marcuse, com base nessa aproximação, seria apresentar as bases de uma modificação cultural e estética da civilização industrial, definindo a função da arte na sociedade moderna. Sua proposta, portanto, diz respeito ao desenvolvimento de um projeto de uma cultura não repressiva, que permita aos homens reatarem com uma ideia mais "correta" acerca da felicidade. E, para tal, é necessária uma mínima compreensão sobre os conceitos anteriormente citados.

O que despertou a atenção de Marcuse, dentre outras inúmeras questões surgidas no pós-guerra, mais especificamente após a Segunda Grande Guerra, foi o poder de integração apresentado pela sociedade industrial moderna, para desqualificar toda e qualquer oposição de caráter artístico e político que viesse a anunciar uma outra via que não fosse a da lucratividade sem limites, no que diz respeito às atividades do homem. O que chamou ainda mais a sua atenção foi a desproporção entre o admirável potencial de libertação, representado pelos progressos técnico, científico e industrial, e a conservação de controles e de métodos repressivos que obrigavam os indivíduos a darem um freio nos seus desejos e nas suas pulsões, para sublimá-las em força de trabalho.

É-nos evidente que Marcuse não nega a necessidade de uma repressão das pulsões, como nos apontou Freud. Entretanto, a tese de Freud lhe pareceu contraditória e, em vários pontos, insuficiente. Para o frankfurtiano, “(...) a própria concepção teórica de Freud parece refutar a sua firme negação da possibilidade histórica de uma civilização não repressiva” (MARCUSE, 1979, p. 28). De acordo com Marcuse, as próprias realizações da civilização repressiva propiciam a criação de precondições para o desaparecimento gradual da repressão; nesse sentido, a teoria de Freud, ela mesma, nos forneceria as razões para rejeitarmos a sua identificação entre civilização e repressão. Questiona Marcuse:

A relação entre liberdade e repressão, produtividade e destruição, dominação e progresso, constituirá realmente o princípio de civilização? Ou essa inter-relação resultará unicamente de uma organização histórica específica da existência humana? Em termos freudianos, o conflito entre princípio de prazer e princípio de realidade será irreconciliável num grau tal que necessite a transformação repressiva da estrutura instintiva do homem? Ou permitirá um conceito de civilização não repressiva, baseada numa experiência fundamentalmente diferente de ser, numa relação fundamentalmente diferente entre homem e natureza, e em fundamentalmente diferentes relações existenciais? (MARCUSE, 1979, p. 28).

Não esqueçamos que o tema central da obra O mal-estar na civilização (1929), de Freud, diz respeito à existência de um antagonismo irremediável entre as exigências pulsionais e as restrições da civilização (princípio de prazer x princípio de realidade). Sabemos que, para Freud, o conceito de sublimação se refere ao destino da sexualidade sob um princípio de realidade repressivo, significando, assim, uma modificação na finalidade e no objeto da pulsão. A sublimação atua, todavia, sobre uma estrutura pulsional precondicionada, que abarca as restrições funcionais e temporais da sexualidade, seu direcionamento para a reprodução monogâmica e a dessexualização de quase todo o corpo: "A sublimação age com a libido assim precondicionada e sua força possessiva, exploradora e agressiva” (MARCUSE, 1979, p. 181).

A transformação repressiva do princípio de prazer antecede a sublimação, sendo que esta carrega consigo os elementos repressivos para produções socialmente úteis. Entretanto, para Marcuse, existem outras formas de sublimação; vale lembrar que Freud nos fala de pulsões sexuais cuja finalidade é inibida, não necessitando serem descritas como sublimadas, mesmo estando estas relacionadas, de maneira bastante estreita, às pulsões sublimadas; Freud as denomina de "pulsões sociais" e apresenta como exemplo as relações afetivas entre pais e filhos, as relações sinceras de amizade e as ligações emocionais propiciadas pelo casamento, que tiveram na atração sexual as suas origens.

Esses conceitos, do ponto de vista marcuseano, estariam bem próximos do reconhecimento da possibilidade de uma sublimação não repressiva, ou seja, do que ele denominou autossublimação. Estabelecido 
o princípio de realidade, a sublimação não repressiva somente passa a ser percebida em seus aspectos de incompletude e marginalidade. De acordo com Marcuse (1979, p. 182), a forma mais desenvolvida da sublimação não repressiva seria a sublimação sem dessexualização. Então, o que isso quer dizer? Quer dizer que as pulsões não são "desviadas" de sua finalidade, sendo gratificadas em atividades e relações que não são consideradas sexuais - do ponto de vista da sexualidade genital "organizada" -, porém, são consideradas como pulsões libidinais e eróticas. Note-se que quando a sublimação repressiva sobrepõe-se, determinando a cultura, a sublimação não repressiva - ou autossublimação - termina por manifestar-se em contradição com toda a esfera de utilidade social. Sendo assim, percebida nessa perspectiva, aparece, então, como negação de toda a produtividade e desempenho aceitos:

\begin{abstract}
A libido só pode tomar a estrada da autossublimação como um fenômeno social: como uma força irreprimida, só pode promover a formação de cultura sob condições que relacionam mutuamente os indivíduos associados na cultivação do meio para fazerem frente a suas crescentes necessidades e empregarem suas crescentes faculdades. A reativação da sexualidade polimórfica e narcisista deixa de ser uma ameaça à cultura e pode levar, ela própria, à criação cultural, se o organismo existir não como um instrumento de trabalho alienado, mas como um sujeito de autorrealização - por outras palavras, se o trabalho socialmente útil for, ao mesmo tempo, a transparente satisfação de uma necessidade individual (MARCUSE, 1979, p. 183).
\end{abstract}

Marcuse afirma que o poder criador de cultura de Eros é a sublimação não repressiva (autossublimação), ou seja, a sexualidade, ao mesmo tempo, nem é desviada nem é impedida de alcançar seu objetivo; muito pelo contrário, ao atingir sua meta, transcende o seu objetivo em favor de outros, numa busca por uma recompensa mais completa. Conforme o frankfurtiano, a definição freudiana de Eros, à luz da ideia de sublimação não repressiva (autossublimação), enriquece ainda mais o seu importante significado. Nesse sentido, há uma conversão do impulso biológico em impulso cultural, com o princípio de prazer revelando a sua própria dialética. Sua finalidade acaba gerando seus próprios projetos de realização, abolindo o esforço (labuta), aperfeiçoando o meio, "conquistando" as doenças, criando o luxo. Essas seriam atividades que fluem diretamente do princípio de prazer, constituindo, ao mesmo tempo, um trabalho que vai associar os indivíduos a grupos maiores.

Por não mais estarem confinados ao comando mutilador do "princípio de rendimento" (produtividade), que representa uma opressão acrescentada ao princípio de realidade, transforma o impulso sem o desviar de sua meta. Pode-se, então, constatar que há sublimação e, como consequência, há também cultura. Complementa Marcuse: "(...) mas essa sublimação decorre num sistema de relações libidinais duradouras e em constante expansão, as quais, em si mesmas, são relações de trabalho” (MARCUSE, 1979, p. 185).

Vamos agora nos ater ao termo dessublimação, concernente também à sublimação no sentido freudiano, empregado aqui com a peculiaridade de estar direcionado ao que Marcuse chama de "dessublimação repressiva", termo que difere de "sublimação não repressiva" ou autossublimação, como já visto. Vamos tentar entender. O princípio de rendimento (produtividade), por ser bastante pragmático, acelera a dessublimação, favorecendo a dessacralização dos velhos tabus, todos eles obstáculos para sua hegemonia. Contudo, essa dessublimação serve também como meio de controle econômico, na medida em que permite que seja atribuído um valor de mercado aos mais variados aspectos da atividade do homem, não escapando nem mesmo as atividades mais privadas. Diz Marcuse no seu prefácioº

A ilustração mais eloquente deste fato é a introdução metódica de elementos "sexy" nos negócios, na política, na publicidade, na propaganda etc. Na medida em que a sexualidade obtém um valor definido de mercado (...) ele se transforma em instrumento de coesão social (MARCUSE, 1963, p. 12). 
Tais considerações parecem distanciar-se do campo da estética, embora Marcuse aí determine o quadro no qual está pensando as relações entre a arte e a sociedade. Faltaria, apenas, a concepção da hipótese de uma civilização não repressiva, onde prefigurariam as obras de arte e a criação artística. Certamente uma utopia, porém, indaga Marcuse se seria ela mais ilusória do que a racionalidade presente nas sociedades modernas, frequentemente insensata e até mesmo irracional.

Na opinião do frankfurtiano, somente a arte, dentre todas as atividades humanas - em sua maioria controladas pela razão -, poderia, ainda, esboçar a sua utopia. Para que isso pudesse vir a acontecer, deveríamos, ao menos, supor que o nosso imaginário e os nossos fantasmas ligados ao inconsciente tivessem a possibilidade de fugir ao controle da razão. Isto feito, a forma estética estaria em condição de expressar o que a civilização do princípio de rendimento tentaria, a todo momento, recalcar, isto é, a imagem de um mundo reconciliado consigo mesmo. $\mathrm{O}$ universo aparente que as projeções imaginárias da arte nos proporcionam, acaba por exprimir a negação do mundo real, o desejo de romper com a racionalidade de uma sociedade.

O relativo otimismo encontrado em Eros e civilização, vinculado diretamente à esperança de realização da sua utopia graças à arte, se "dissolve" nas páginas de O homem unidimensional (1964). De acordo com Marcuse, a "unidimensionalidade" diz respeito especificamente à submissão de todas as atividades do homem ao sistema mercantil, ao comércio lucrativo e sua sujeição à produtividade, ao princípio de rendimento. Na sua perspectiva, o desenvolvimento da racionalidade tecnológica estaria em vias de liquidar "(...) os elementos opostos e transcendentes da cultura superior"; tais elementos seriam "(...) vítimas do processo de dessublimação que é preponderante nos setores avançados da sociedade contemporânea" (MARCUSE, 1964, p. 81).

Como se pode perceber, a aceitação e interiorização das regras do jogo por parte das pessoas governadas demonstram, de forma nítida, como funciona a dessublimação repressiva, visto que ela, de alguma forma, garante o estabelecimento de uma sociedade coesa. Para Marcuse, as conquistas e os fracassos experimentados pela sociedade tornavam inválida sua cultura superior. O que ocorria não era a degradação dessa cultura, transmutando-se em cultura de massa, mas, sim, a refutação dessa mesma cultura pela realidade, visto que, para o frankfurtiano, a realidade sempre ultrapassa a sua cultura: "O homem pode hoje em dia fazer mais do que os heróis e semideuses da cultura; resolveu muitos problemas insolúveis. Mas também traiu as esperanças e destruiu a verdade que eram preservadas nas sublimações da cultura superior" (MARCUSE, 1964, p. 81). O que se pode observar é que a cultura superior sempre se mostrou antagônica em relação à realidade social, onde somente uma pequena parcela de indivíduos privilegiados usufruía de suas vantagens, representando seus ideais. Esses dois lados opostos da sociedade sempre coexistiram, sendo a cultura superior uma cultura que tende a acomodar, enquanto a realidade social raramente se deixa perturbar pelos ideais e verdades dessa mesma cultura. Comenta Jimenez:

A arte e a cultura não escapam a esta lei de integração na sociedade unidimensional. Mais do que nunca, para Marcuse, a cultura tende a tornar-se afirmativa. Ela não critica mais a sociedade propondo ao público uma outra maneira de viver, suscitando uma aspiração para transformar a existência presente. Através do herói nacional, do gângster, da estrela, do grande patrão, da figura carismática, ela se contenta em expor variantes de uma vida idêntica, e essas variantes não "servem mais para negar a ordem estabelecida, elas servem para afirmá-la" (JIMENEZ, 2008, p. 346).

Concordamos plenamente com Jimenez, quando ele constata que, sem maiores esperanças no futuro, Marcuse aguardava uma melhora do sistema, o que não o impediu de estar sempre ao lado das minorias. Descrente, de certa forma, no que diz respeito ao futuro reservado à cultura e à arte nas sociedades desenvolvidas, ele recusa, veementemente, todo e qualquer niilismo. Muito pelo contrário, num mundo 
caracterizado pela dessublimação de tudo e pelo sacrifício de todos voltado aos interesses econômicos, ele se mostra convencido de que a permanência de uma suspeita de sublimação pode, sim, manifestar-se como um ato de resistência. E dada a importância desse ato de resistência, creio, portanto, que se justifique o que, inicialmente, fora proposto, a saber, a compreensão do conceito de sublimação, assim como suas derivações, levando em consideração a perspectiva estética marcuseana.

\section{REFERÊNCIAS}

FREUD, S. (1988a). Moral sexual civilizada e doença nervosa moderna (1908). In: Obras Completas, vol. IX. Direção de Jayme Salomão. Rio de Janeiro: Imago.

(1988b). O Moisés de Michelangelo (1914). In: Obras Completas, vol. XIII.

Direção de Jayme Salomão. Rio de Janeiro: Imago.

(2010). O mal-estar na civilização (1929). In: Obras Completas, vol. XVIII.

Tradução de Paulo César de Souza. São Paulo: Cia. das Letras.

HADDOCK-LOBO, R. (Org.) (2010). Os filósofos e a arte. Rio de Janeiro: Rocco.

JIMENEZ, M. (2008). O que é estética? Tradução de Fulvia M. L. Moretto. São Leopoldo: Unisinos.

MARCUSE, H. (1963). Eros et civilisation. Contribution a Freud. Traduit de l'anglais par Jean-Guy Nény et Boris Fraenkel. Paris: Minuit.

lauteur. Paris: Minuit.

(1964). L'homme unidimensionnel. Traduction de Monique Wittig revue par

(1979). Eros e civilização. Uma interpretação filosófica do pensamento de

Freud. Tradução de Álvaro Cabral. Rio de Janeiro: Guanabara Koogan.

NASIO, J. D. (1995). Lições sobre os 7 conceitos cruciais da psicanálise. Tradução de Vera Ribeiro. Rio de Janeiro: JZE.

\section{NOTAS}

1. Esse prefácio consta na edição francesa, elencada nas referências. Tradução nossa. 